\title{
O EXERCICIO DA CIDADANIA E A GESTÃO E RESPONSABILIDADE SOCIAL
}

\section{THE PRACTICE OF CITIZENSHIP AND THE ADMINISTRATION AND SOCIAL RESPONSIBILITY}

\author{
Lauci Aparecida Cavalett \\ SENAI/SC - Joinville, E-mail: professoralauci@uol.com.br
}

Resumo: $\mathrm{O}$ artigo apresenta literaturas atualizadas recorrentes à responsabilidade social e exemplifica a eficiência das diferentes formas de estrutura organizacional em lidar com implantação, ações e práticas de responsabilidade social. Na qualidade de profissional da educação, compreende-se que é dever da Universidade ir à busca de alternativas, para solucionar problemas emergentes na sociedade. Também compete aos programas de pesquisa e extensão, conceber e propor medidas que minimizem a crise que se está atravessando no presente momento. E as empresas podem contribuir e participar de projetos em conjunto com as instituições educacionais, estimulando a participação de seus funcionários a partir de projetos relacionados à realidade de cada organização. A relevância do tema se situa, portanto, também dentro da necessidade que a instituição educacional e empresarial tem de dar respostas à demanda da sociedade para a questão do trabalho, da empregabilidade, dos programas de inclusão e da responsabilidade social.

Palavras-chave: Responsabilidade social; Projetos sociais; Prática da leitura.

Abstract: This article presents a review of current literature about social responsibility and reveals different examples of successful types of organizational structure aimed at dealing with implantation, actions and practices of social responsibility. In education, it is understood that it is the duty of the university to search for alternatives in solving problems emerging in our society. It is also the task of extension and research programs to conceive and propose measures aimed at minimizing the crisis that we are experiencing at this moment. In addition to this, companies may contribute and take part of projects with educational institutions, stimulating their employees to take part in projects related to the situation of the company. The relevance of this theme is therefore found also in the necessity of the educational and managerial institution to give answers to the questions of the society about the labor issue, the employment, the inclusion programs and social responsibility.

Key-words: Social Responsibility; Social Projects; Reading Practice.

\section{INTRODUÇÃO}

Este estudo pretende analisar um dos aspectos relevantes na estrutura organizacional referente ao exercício de cidadania e responsabilidade social, tanto em espaços escolares como não escolares. Isso significa que as instituições educacional e empresarial devem buscar entender e otimizar sua influência, guiada por uma estratégia de avaliação efetiva. A premissa básica do problema de investigação é a de que o ambiente institucional que envolve a atividade de negócios define o tipo de comportamento das empresas em relação às ações de responsabilidade social a serem implementadas. 
A gestão da qualidade é um modelo gerencial que responde ao how make (como fazer) em uma organização. Igualmente importante é what make (o que fazer), que diz respeito ao plano de desenvolvimento das instituições educacionais, o real planejamento estratégico. A partir desses dois componentes e do envolvimento/comprometimento dos colaboradores (with who to make) que dependerá o sucesso ou o fracasso do programas de gestão da qualidade educacional.

\title{
2 CONTEXTUALIZANDO A POLÍTICA EDUCACIONAL BRASILEIRA
}

\begin{abstract}
Um homem que trabalha com as mãos é um operário. Um homem que trabalha com as mãos e o cérebro é um artesão. Mas um homem que trabalha com as mãos, o cérebro e o coração é um artista (Louis Nizer ).
\end{abstract}

A Constituição Federal de 1988 já apontava para modificações necessárias na gestão educacional, objetivando qualidade. Do conjunto dos dispositivos constitucionais sobre educação, orientado pelos princípios arrolados no artigo 206, colocam-se a garantia de um padrão de qualidade do ensino e a gestão democrática deste (BRASIL, 1989). A privatização tem na autonomia da escola, no fomento à participação comunitária e na gestão democrática seus principais meios de concretização, na medida em que "[...] possibilitam a captação direta e indireta de recursos financeiros, a mobilização de recursos humanos voluntários, e a disponibilização de recursos materiais e físicos suplementares" (FREITAS, 1998). Tais estratégias potencializam o compartilhamento da tarefa educacional e a viabilização de novas formas de provisão da educação.

A política educacional brasileira pauta-se por uma racionalidade instrumental e utilitarista da educação. Por um lado, vista como ferramenta da competitividade e condição de desenvolvimento econômico e de inserção do país na "nova" ordem econômica mundial. Por outro, vista como ferramenta da governabilidade, condição de produção da cidadania requerida pela sociabilidade capitalista em configuração inclusive para a consolidação da ordem democrática requerida pela mesma (CARDOSO, 1994 apud FREITAS, 1998).

Segundo Freire (1997, p.15), “conhecer é tarefa de sujeitos, não de objetos. E é como sujeito e somente enquanto sujeito, que o homem pode realmente conhecer". Portanto, no processo de aprendizagem, só aprende verdadeiramente aquele que se apropria do aprendido, transformando-o, gerando com isto agentes responsáveis, co-autores destas novas construções e transformações.

É necessário que a educação profissional seja inserida de forma mais efetiva na reavaliação de seus procedimentos estratégicos e metodológicos de educação, pois só mudamos conscientemente aquilo que reconhecemos, e só assim saberemos o que, onde, e como mudarmos. Ter competência para participar de discursos cada vez mais sofisticados, diz Moraes (2006), é parte do processo de assumir-se sujeito. Mas para isso, devemos perceber que o conhecer e o aprender não são atos de pessoas isoladas, mas distribuem-se entre os participantes; dão-se junto com os outros; constituem atividades de natureza social.

O documento editado pela UNESCO em Paris (1998), que traz a Declaração Mundial sobre Educação Superior no Século XXI, considera como missão da educação superior educar, 
formar e realizar pesquisas; e como função a ética, a autonomia, a responsabilidade e a função preventiva. Associe-se aqui que a educação compete também preocupar-se com a empregabilidade, pois é um tema emergente em nossos dias. Ela se refere à capacidade humana de gerir o próprio destino e prover meios para a sobrevivência.

As crises que se sucedem na sociedade conduzem a uma mudança de paradigmas que a estão levando para além da sociedade industrial (TOFFLER, 1995; CAPRA, 1996). O fato tem causado impactos sobre a organização da sociedade em geral, bem como sobre a identidade das pessoas e suas relações sociais e de trabalho.

O avanço do mercado global e da tecnologia está afetando os setores da economia, redefinindo as relações que vinham se reproduzindo segundo os mesmos padrões desde as primeiras décadas do século XX. No decorrer deste século, passou-se a exigir do cidadão uma acurada visão de mundo, elevada à maestria pessoal, sem a qual não mais existe a empregabilidade (MENEGASSO, 1998). As pessoas estão distantes dessa habilidade, já que foram quase sempre educadas para empregos em que alguém por elas assumia os riscos. Esse fato traz como resultado vários problemas sociais. O surgimento de uma classe de trabalhadores subempregados e mal pagos afeta indevidamente aqueles que já consideram suas oportunidades de emprego restritas, aumentando os problemas de discriminação por sexo, raça, idade e também aos deficientes (TOFFLER, 1995).

Pode-se, a partir da discussão apontada, afirmar que o emprego necessita ser reconceitualizado no vocabulário de muitos. À medida que o mundo se torna mais interligado e as relações entre os negócios mais competitivos, mais necessários se torna aprender formas diferentes de fazer aquilo que, até então, sempre deu certo. O trabalho está cada vez mais ligado ao "aprendizado", já não basta ter uma única pessoa aprendendo pela organização toda.

O aprendizado faz parte da natureza humana para aprender algo novo que nos instiga, que nos desafia, necessitamos de condições necessárias para essa aprendizagem. Compreender o significado mais profundo de "aprender" poderá ser a chave para essa questão, pois a aprendizagem perdeu seu significado básico no mundo contemporâneo e passou a ser sinônimo de "assimilar informação", o que tem uma remota conotação com o verdadeiro significado da palavra.

A verdadeira aprendizagem está intimamente relacionada com o que significa para o ser humano. Por seu intermédio nós recriamos, tornamo-nos capazes de fazer aquilo que não fazíamos antes, adquirimos uma nova visão do mundo e da nossa relação com ele, ampliamos nossa capacidade de fazer parte do processo regenerativo da vida. Esse momento que a sociedade brasileira está vivendo informa-nos que a qualidade do pensamento até agora utilizada não resolve os desafios que se acumulam e se agravam. Não adianta ficarmos debitando a crise exclusivamente aos políticos.

O exercício da cidadania pressupõe o apoio a ações de interesse social, podendo incluir a educação e a assistência comunitária, a promoção da cultura, do esporte e do lazer, e a participação no desenvolvimento nacional, regional ou setorial. A liderança na cidadania implica influenciar outras organizações, públicas ou privadas, a se tornarem parceiras nestes propósitos e, também, estimular as pessoas de sua própria força de trabalho a se engajarem em atividades sociais (FUNDAÇÃO NACIONAL DA QUALIDADE, 2007, p. 05).

E-Tech: Tecnologias para Competitividade Industrial, Florianópolis, v. 1, n. 2, p. 1-10, 2º. Sem., 2008. 
O grande desafio é o de criar um Brasil mais humano, porque proporciona a todos as mesmas oportunidades de crescimento e desenvolvimento, de trabalho e de exercício de nossa cidadania, garantida pela Constituição brasileira (1988). A base de todo esse processo está na educação e só o papel atuante dos cidadãos resgatará o valor e a satisfação contida naquele que ao fazer, também se realiza enquanto pessoa e profissional.

\subsection{A IMPORTÂNCIA DA LEITURA PARA A CONSTRUÇÃO DE SABERES}

O conhecimento pode ser encontrado através da leitura e esta, por sua vez, possibilita formar uma sociedade consciente de seus direitos e de seus deveres; possibilita que estes tenham uma visão melhor de mundo e de si mesmos. Mas onde e como encontrar informação e/ou conhecimento? Qual(is) sujeito(s) poderia(m) mediar as fontes de informação? $\mathrm{O}$ conhecimento está disponível nas mais diversas fontes de informação, sejam formais registrado - em livros, artigos, entre outros, sejam informais onde se destaca a conversa direta, face a face e se tem o acúmulo do conhecimento tácito ou implícito, fruto das experiências vivenciadas ao longo do tempo, da troca de informação, de conhecimento, - externalizados mas não registrados.

De acordo com Morin (1999), a racionalidade do logos, experimentou, através das ciências, da filosofia e da técnica, um notável desenvolvimento ao longo da história e, em especial, nos últimos séculos. Entretanto, racionalidade e técnica, freqüentemente tidas como características do ser humano, já estavam presentes antes do homo sapiens, e podem ser encontradas também nos comportamentos dos animais em busca da sobrevivência.

Todo acontecimento cognitivo necessita da conjunção de processos energéticos, elétricos, químicos, fisiológicos, cerebrais, existenciais, psicológicos, culturais, lingüísticos, lógicos, ideais, individuais, coletivos, pessoais, transpessoais e impessoais, que se encaixam uns nos outros. O conhecimento é, portanto, um fenômeno multidimensional, de maneira inseparável, simultaneamente físico, biológico, cerebral, mental, psicológico, cultural, social (MORIN, 1999, p. 18).

A identidade se dá ao longo de nossas experiências, no contato com o grupo, na representação de papéis que assumimos ao longo da vida. Ela é em certa medida pressuposta, a partir de uma série de expectativas e representações preexistentes no indivíduo, mas é colocada em conflito dentro da prática cotidiana.

A prática de gerenciar tem salientado a necessidade de tornar conhecida a finalidade da organização, a fim de que seus dirigentes, gerentes e demais empregados possam canalizar seus esforços para atingi-la e a fim de que a organização seja considerada legítima pela sociedade. Outra tendência tem sido definir a finalidade a partir de processos mais participativos, com um número maior de empregados contribuindo para esta tarefa (TENÓRIO, 1997, p.18).

O convívio com o grupo permite o confronto entre as pessoas e cada um vai se construindo nesse processo de interação, por meio das constatações de semelhanças e diferenças entre nós e os outros. E é nesse processo que desenvolvemos a individualidade, a nossa identidade e a consciência de nós mesmos.

E-Tech: Tecnologias para Competitividade Industrial, Florianópolis, v. 1, n. 2, p. 1-10, 2º Sem., 2008. 
Nos mais diversos níveis, os objetivos da educação voltam-se à formação de competências, com conhecimentos e para atuação no meio social, o que demanda grades curriculares e metodologia de ensino e de avaliação, inclusive nas ações pedagógicas. Conforme apontam as orientações do MEC, o desenvolvimento de competências supõe uma metodologia de ensino que integra atividades, projetos e exercícios que instiguem desafios nos indivíduos.

No Brasil, a Lei de Diretrizes e Bases, Lei 9.394/96, inseriu no país um cenário de transformações dentro de um contexto de globalização: a busca pela sintonia entre a escola e o mundo do trabalho diante das mudanças tecnológicas aceleradas, criando um perfil de profissional, polivalente, flexível, numa perspectiva de desenvolvimento progressivo de competências reconhecidas pelo mercado de trabalho. Um dos grandes desafios dessa nova sociedade é o aprofundamento das desigualdades sociais sobre o eixo do acesso e uso da informação e isso requer a intervenção em níveis locais e globais. Pensar no futuro da educação é necessidade primordial não só das comunidades científicas, mas também das políticas públicas e haver consonância entre os objetivos das pesquisas da primeira e as iniciativas propostas pela segunda. Para Ladislau Dowbor (1999),

A transformação é profunda. No decorrer de meio século, passamos de uma visão filantrópica, de generosidade assistencial, de caridade, de um tipo de bálsamo tranquilizador para as consciências capitalistas, para a compreensão de que a área social se tornou essencial para as próprias atividades econômicas.

O homem criou objetos para satisfazer as suas necessidades práticas, como as ferramentas para cavar a terra e os utensílios de cozinha. E criou a escrita, e consequientemente a leitura para registrar seu saber e pensar, para divulgar as suas crenças (ou as de outros), para estimular e distrair a si mesmo e aos outros, para explorar novas formas de olhar e interpretar objetos e cenas. Assim, é possível fazer da leitura um instrumento para a mobilização e organização da comunidade em busca de uma melhor qualidade de vida.

Colocar o desenvolvimento social e a qualidade de vida como objetivos, como finalidade mais ampla da sociedade, "tem repercussões profundas, na medida em que o social deixa de ser apenas um setor de atividades, para se tornar uma dimensão de todas as nossas atividades" (DOWBOR, 1999). O domínio da língua tem estreita relação com a possibilidade de plena participação social, pois é por meio dela que o homem se comunica, tem acesso à informação, expressa e defende pontos de vista, partilha ou constrói visões de mundo, produz conhecimento.

\footnotetext{
Deste modo, pensar, conhecer, saber, intuir e ousar são as mais recentes palavras que devem dominar o vocabulário dos indivíduos que compõem a sociedade. Como obter um senso crítico senão mediante a leitura dos textos que atuam sobre: [...] os esquemas cognitivos do leitor. Quando alguém lê algo, aplica determinado esquema alterando-o ou confirmando-o, mas principalmente entendendo mensagens diferentes de seus esquemas cognitivos, ou seja, as capacidades já internalizadas e o conhecimento de mundo de cada um são diferentes (KRIEGL, 2002, p.01-12).
}

Assim, um projeto educativo comprometido com a democratização social e cultural atribui à escola a função e a responsabilidade de garantir a todos os seus alunos o acesso aos saberes lingüísticos necessário para o exercício da cidadania, direito inalienável de todos. Essa responsabilidade é tanto maior quanto menor for o grau de letramento das comunidades em que vivem os indivíduos. 


\section{CONCLUSÃO}

O exercício da cidadania é feito mediante direitos e deveres e para tanto é preciso haver uma maior e mais justa democratização do acesso à informação, ao conhecimento. $O$ conhecimento constrói-se no sujeito, é tarefa de significação (apropriação). Para que isto ocorra é necessário que a informação esteja vinculada aos contextos e experiências do leitor. Este processo é lento, reflexivo, individual ainda que o produto do conhecimento seja, a posteriori, socializado.

Continuar perseverando no objetivo maior de conscientizar a sociedade para a relevância da leitura para a formação de uma sociedade consciente e estimular as empresas para a criação de programas de leitura e reflexão sobre a qualidade dos programas e projetos existentes com adaptação às demandas informacionais da sociedade atual é o principal foco deste estudo.

\section{REFERENCIAS}

BRASIL. Constituição 1988. Brasília, DF: Senado Federal, 2000.

CAPRA, Fritjof. A teia da vida: uma nova compreensão científica dos sistemas vivos. São Paulo : Cultrix, 1996.

DEMO, Pedro. Educar pela pesquisa. São Paulo: Autores Associados, 1997.

DOWBOR, Ladislau. Gestão social e transformação da sociedade. Ladislau Dowbor Artigos Online, São Paulo, nov. 1999. Disponível em: <http://dowbor.org/8_gestaosocial.asp>. Acesso em: 17 jan. 2008.

FREIRE, Paulo. A importância do ato de ler: em três artigos que se completam. São Paulo:Cortez, 1993.

. Pedagogia da autonomia. São Paulo: Paz e Terra, 1997.

FREITAS, Dirce Nei Teixeira de. A gestão educacional na interseção das políticas federal e municipal. Revista Faculdade de Educação. São Paulo, v.24, n. 02, jul./dez. 1998.

FUNDAÇÃO NACIONAL DA QUALIDADE. Cadernos de excelência: Sociedade. São Paulo, 2007. (Série Cadernos de Excelência, n. 4)

KRIEGL, Maria de Lourdes de Souza.Leitura: um desafio sempre atual. Revista PEC, Curitiba, v. 2, n.1, p. 1-12, jul. 2001-jul. 2002.

LÚDKE, Menga; ANDRÉ, Marli Elisa D. A. Pesquisa qualitativa em Educação: abordagens qualitativas. São Paulo: EPU, 1986 ( Temas básicos de educação e ensino).

MENEGASSO, Maria Ester. O declínio do emprego e a ascensão da empregabilidade: um protótipo para promover a empregabilidade na empresa pública do setor bancário. Tese 
(Doutorado em Engenharia de produção e sistemas) - Universidade Federal de Santa Catarina. Florianópolis, 1998.

MORIN, Edgar. O Método 3: O conhecimento do conhecimento. 2.ed. Porto Alegre: Sulina.

MORAES, Roque. (Org.) Construtivismo e ensino de ciências: reflexões epistemológicas e metodológicas. Porto Alegre: EDIPUCRS, 2003.

TENÓRIO, Fernando Guilherme. (org.) Gestão de ONG's: Principais Funções Gerenciais. 2.ed. Rio de Janeiro: Editora da Fundação Getúlio Vargas, 1997. 139p.

TOFFLER, Alvin. A terceira onda. 21. ed. Rio de Janeiro : Record, 1995.

UNIVERSIDADE DE BRASÍLIA. Projeto de Leitura e Produção de texto, ago. 2007. Disponível em: http://aprender.unb.br/mod/forum/discuss.php?d=32722 . Acesso em: 18 jan. 2008.

UNESCO. Declaração Mundial sobre Educação Superior. Paris, 1998.

\section{BLIOGRAFIA CONSULTADA}

AMADEO, Edward. A evolução recente da oferta de trabalho e do emprego no Brasil. Notas sobre o mercado de trabalho. Brasília, Ministério do Trabalho, n. 1, jul. 1998.

AMBONI, Nério. O caso CECRISA S.A.: uma aprendizagem que deu certo. Tese (Doutorado em Engenharia de produção e sistemas) - Universidade Federal de Santa Catarina. Florianópolis, 1997.

ASSOCIAÇÃO BRASILEIRA DE NORMAS TÉCNICAS. Informação e documentação referências - elaboração: NBR 6023. Rio de Janeiro: ABNT, 2002.

Informação e documentação - apresentação de citações em documentos: NBR

10520. Rio de Janeiro: ABNT, 2002.

Informação e documentação - trabalhos acadêmicos - apresentação: NBR 14724. Rio de Janeiro: ABNT, 2005.

ABNT, 2003.

Numeração progressiva das seções de um documento: NBR 6024. Rio de Janeiro:

Informação e documentação - Projeto de Pesquisa - Apresentação: NBR

15287/05. Rio de Janeiro:ABNT,2005.

ASSMANN, Hugo. Reencantar a educação. Petrópolis/RJ: Vozes, 1998.

BACHELARD, Gaston. A formação do espírito científico: contribuição para uma psicanálise do conhecimento. Rio de Janeiro: Contraponto, 1996. 
BARNEY, J.; HESTERLY, W. Economia das organizações: entendendo a relação entre as organizações e a análise econômica. In: CLEGG, S.; HARDY, C.; NORD. W. Handbook de Estudos Organizacionais. São Paulo: Atlas, 2004. v. 3.

BARRETO, Ângela Maria. Leitura: suas categorias de produção de sentidos nas novas e antigas formas de acesso à informação. $O$ ideal de disseminar: novas perspectivas, outras percepções. Salvador: EDUFBA, 2006.

BERNARDO, Gustavo. Educação pelo argumento. Rio de Janeiro: Rocco, 2000.

CAPRA, Fritjof. O ponto de mutação. São Paulo : Cultrix, 1982.

CASALI, Alípio et al. Empregabilidade e educação: novos caminhos no mundo do trabalho. São Paulo : EDUC, 1997.

CASE, Thomas A., CASE, Silvana, FRANCIATTO, Claudir. Empregabilidade: de executivo a consultor bem-sucedido. São Paulo : Makron Books, 1997.

CHIZZOTTI, Antonio. Pesquisa em ciências humanas e sociais. São Paulo: Cortez, 1998.

EASTERBY-SMITH, M; ARAUJO, L.; BURGOYNE, J. (org.) Aprendizagem

organizacional e organização de aprendizagem: Desenvolvimento na prática e na teoria. São Paulo: Atlas, 2001. [cap. 2 e 4 ]

DIAS, Claudia. Disponível em: <http://www.geocities.com/claudiaad/qualitativa.html >. Acesso em: 08 jul. 2006.

FERRETTI, Celso João et al. Tecnologias, trabalho e educação: um trabalho multidisciplinar. 3. ed. Petrópolis : Vozes, 1994.

FORSLIND, Ann. Pinturas: Jogos e Experiências. São Paulo: Callis, 1997.

FREIRE, Paulo. A importância do ato de ler: em três artigos que se completam. São Paulo:Cortez, 1993. 1985.

; FAUNDEZ, Antonio. Por uma pedagogia da pergunta. Rio de Janeiro, Paz e Terra,

GAUDENCIO, Paulo. Men at work: como o ser humano se torna e se mantém produtivo. São Paulo: Memnon, 1995.

HARTLEY, Jean F. Case studies in organizational research. In: CASSELL, Catherine \& SYMON, Gillian (Ed.). Qualitative methods in organizational research: a practical guide. London: Sage, 1994. 253p. p. 208-229. Tradução:

INSTITUTO BRASILEIRO DE INFORMAÇÃO, CIÊNCIA E TECNOLOGIA. A informação: tendências para o novo milênio. Brasília, 1999.

HISTÓRICO do Senai de Joinville. Disponível em: <http://www.sc.senai.br>. Acesso em 10 jun. 2006.

E-Tech: Tecnologias para Competitividade Industrial, Florianópolis, v. 1, n. 2, p. 1-10, 2º. Sem., 2008. 
MARTIN, J.; FROST, P. Jogos de Guerra da cultura organizacional: a luta pelo domínio intelectual. In : CLEGG, S.; HARDY, C.; NORD. W. Handbook de estudos organizacionais. v. 2. São Paulo: Atlas, 2001

MARTINS, Gilberto de Andrade. Estudo de caso. Disponível em:

$<$ http://www.focca.com.br/cac/textocac/Estudo_Caso.htm>. Acesso em 10 jul.2006.

MORAES, Roque. (Org.) Construtivismo e ensino de ciências: reflexões epistemológicas e metodológicas. Porto Alegre: EDIPUCRS, 2003.

MORIN, E. Ciência com consciência. Tradução Maria Alexandre e Maria Alice Sampaio Dório. Rio de Janeiro: Bertrand Brasil, 1996.

MOSCOVICI, Fela. Renascença organizacional. 6.ed. Rio de Janeiro: José Olympio, 1996.

NKOMO, S. M.; COX, T. Diversidade e identidade nas organizações. In: CLEGG, S.R . et al., Handbook de estudos organizacionais. v.1 São Paulo: Atlas, 1999.

PARTICIPANDO da conversa: Construindo competências argumentativas na fala e na escrita. Disponível em: <http://www.pucrs.br/manualred/textos/texto4.php>. Acesso em: 10 jun. 2006.

PERRENOUD, Philippi. Dez novas competências para ensinar. Porto Alegre: Artes Médicas, 2000.

RONCA, Antônio Carlos Caruso. Técnicas pedagógicas: domesticação ou desafio à participação? Petrópolis: Vozes, 1980.

ROS, M.; GOUVEA, V.V. Psicologia Social dos Valores Humanos. São Paulo: SENAC, 2006. [Cap.2, 5,13]

ROSS, S. A.; WESTERFIELD, R. W.; JAFFE, J. F. Administração financeira: Corporate finance. 2.d. São Paulo: Atlas, 2002.

RUAS, R.; ANTONELLO, C. S.; BOFF, L. H. (org.) Aprendizagem organizacional e competências. Porto Alegre: Bookman. 2004. [cap.1]

TAMAYO, A.; PORTO, J.B. Valores e comportamento nas organizações. Rio de Janeiro: Vozes, 2005. [Prefácio]

THOMAS Jr, R. A diversidade e as organizações do futuro. In: HESSELBEIN, F.; MARSHALL, G.; BECKHARD, R. A organização do futuro. São Paulo: Futura, 2001.

TRIVIÑOS, Augusto Nibaldo Silva. Introdução à pesquisa em ciências sociais: a pesquisa qualitativa em educação. São Paulo : Atlas, 1987.

VASCONCELOS, F.; BRITO, L.A. L. Vantagem competitiva: O construto e a métrica. Revista de Administração de Empresas. v.44, n.2, p. 51-63, Abr-jun 2004. Disponível em: 
$<$ http://www.rae.com.br/rae/index.cfm?FuseAction=Artigo\&ID=2026\&Secao=ESTRAT\%C3

$\% 89$ GIA $\&$ Volume $=44 \&$ Numero=2\&Ano=2004> . Acesso em: 01 out. 2007.

VOLBERDA, H. W. Crise em estratégia: fragmentação, integração ou síntese. Revista de Administração de Empresas, v. 4, n. 4, Seção Fórum de Estratégia, 2004. Disponível em: <www.rae.com.br/rae/index.cfm>. Acesso em: 01 out. 2007.

ZARIFIAN, P. O Modelo Competências: trajetórias históricas, desafios atuais e propostas. São Paulo: SENAC, 2003. [Cap. 1, 2, 3].

Originais recebidos em: 18 abr. 2008.

Texto aprovado em: 23 jun. 2008.

\section{SOBRE A AUTORA}

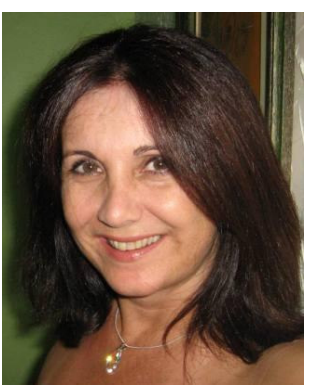

\section{Laucí Aparecida Cavalett}

Doutoranda em Educação na UPAP , com ênfase em Responsabilidade social - NBR 16001. Mestrado em História pela Universidade Federal de Santa Catarina (1998). Especialização em História Social pela UNIVALI (1995). Graduação - Licenciatura Plena em EAD: Formação Pedagógica para formadores de ensino profissionalizante, pela UNISUL (2007). Graduação em História - Licenciatura plena - pela Universidade da Região de Joinville (1990). Coordenadora Pedagógica em projetos especiais na UNIESP - SP e atualmente participa do Plano setorial de qualificação dos trabalhadores PLANSEQ. Experiência educacional na área corporativa e no ensino superior, com ênfase em metodologia da pesquisa, atuando principalmente nos seguintes temas: metodologia e pesquisa; estágio, projeto de pesquisa, monografias para graduação e pós-graduação. Assessoria em produção de materiais didáticos para os cursos de Educação à distância - EAD.

E-mail: professoralauci@uol.com.br 